\title{
Biotechnology, farm management and local agricultural development
}

\author{
Maria Teresa Gorgitano ${ }^{*}$ and Valeria Sodano ${ }^{\mathrm{G}}$
}

\section{INTRODUCTION}

The paper analyses the potential effects of biotechnology innovations in agriculture, referring to the case of the processed tomato sector in Southern Italy. To date, there are not yet available biotechnology commercial products, but the spreading life-science revolution will soon offer new opportunities also in this sector. After a brief presentation of the current competitive position of the examined industry, the analysis of biotechnological impact is carried out in two stages.

Primarily, an analysis of the potential demand for biotechnologies is conducted, stemming from the results obtained in a wide study on the demand for innovation by farmers in Southern Italy. Moreover perception and acceptance of biotechnologies, by different operators along the tomato "filiera", are investigated through focused interviews.

In the second stage, by drawing the current research effort and comparing the potential innovation with the expressed needs on the demand side, the economic impact of biotechnologies is described taking into account the complex institutional problems affecting the sector. In this stage the analysis is limited to a qualitative ground and doesn't face environmental and ethical problems related to genetically modified food.

In the concluding section, the results are connected to the current discussion on GMOs regulatory policies, demonstrating that in some weak institutional frameworks, like in Southern Italy and in underdeveloped countries, the social control of risks and benefits associated to the new technologies is very hard to achieve, regardless of the chosen policy instrument.

\section{THE ITALIAN PROCESSED TOMATO SECTOR}

Italy is the second world producer of processed tomato and supplies about $50 \%$ of the UE total demand. The processing industry is concentrated in two regions, localized one in Central Italy (Emilia) and the other in Southern Italy (Campania). Different from Emilia, Campania is characterized by the three following elements: (1) agriculture production is located out of the region and is concentrated in Puglia, which is near by; (2) firms are smaller, while Emilia accounts for $15 \%$ and $32 \%$ of respectively total domestic firms and production, Campania supplies $50 \%$ of production and $60 \%$ of firms; (3) Campania is strongly specialized in traditional products, and is the world leader in the peeled tomato, accomplishing $80 \%$ of the total supply.

The tomato industry quickly expanded in the seventies and in the eighties, driven by the increasing demand and by some important innovations, such as (a) the development of hybrids with enhanced yield and quality, (b) the diffusion of picker and seeding machines, (c) the modernization of processing plants.

During the nineties demand increased very slowly and industry tried to keep the sector lively by introducing new products, like prepared flavoured sauces and spiced tomatoes, added to the traditional ones (i.e. peeled tomato, concentrated sauce and pulp sauce).

\footnotetext{
Dipartimento di Economia e Politica Agraria - Università di Napoli Federico II - Via Università, 96 - 80055 Portici Italy tel. +39 081 5972111- fax +39 0817755143 - E-mail gorgitan@unina.it or vsodano@unina.it.
} 
The most important event which influenced the sector evolution during the last twenty years is the UE support (reg. 1152/78 and 2200/96) which provides subsidies to processors for fixed quotas. To receive the subsidies, processors must pay the farmer a price not smaller than the target price annually set by the Commission. Moreover, processors are constrained to make purchasing contracts with the farmers' associations instead of with separate farmers. The UE intervention allowed the sector to survive in a framework of very low competitiveness with respect to the world market, where prices are about $40 \%$ smaller than the domestic minimum guaranteed price.

To date, the sector lies in the maturity stage of its life cycle. Profits are still positive, but operators are seriously concerned about negative signals from price trends. The situation can quickly worsen if the UE decides to cut the support and this eventuality negatively affects expectations and investments among the operators.

\section{THE EMPIRICAL ANALYSIS OF THE INNOVATION DEMAND}

The analysis of innovation demand in the Southern processed tomato sector was conducted through a field survey organized in two stages. In the first stage, we preliminary explored innovation problems by interviewing exponents of different bodies acting in the "filiera", such as processing firms, producer associations and regional agricultural development services. In the second stage, we studied the relationships between farmers' structural and managerial characteristics and their need for innovation. To this aim we developed a specified questionnaire and submitted it to a large sample of growers from Puglia and Campania, which sell the local processors.

\subsection{The perception of innovation needs by the agriculture related sectors}

\section{I- Processing firms}

Processors are mainly interested in product innovation to achieve two goals: (a) to make use of plant machinery throughout the year; (b) to differentiate the production to match new consumers attitudes.

Firms selling through supermarket private labels are concerned with quality control and guarantee. They also highlight the increasing demand of retailers for tomatoes obtained by following integrated techniques of production.

Firms selling branded products generally focus on product differentiation in niche markets, such as regional or organic ones. Some people are attracted by functionally engineered food, such as dietary tomatoes with a higher concentration of antioxidants (lycopene, and flavanoids), that are supposed to prevent cancer.

All of the companies are interested in innovations that raise the productivity of the cycle of transformation, through either an increase in the Brix degree, or a very high resistance to peeling.

Biotechnologies are generally disregarded, firstly because of the current mistrust shown by European consumers. Secondly because the applications that have been proposed up to now, have not responded to the specific needs of firms operating in Campania.

\section{II-Producer associations}

Producer associations are made up of producer cooperatives that are very heterogeneous in sizes and behaviors. The associations are predominantly from the Campania region, while cooperatives are equally distributed between Campania and Puglia. The distance of the associations management from farmers account for the low 
interest they exhibit in agriculture innovation problems. Many managers of the associations have a clear perception of the most urgent technical problems, such as virus prevention. Nevertheless, they tackle farmers needs in a very lazy way. Very few cooperatives provide technical assistance for their members and more often the job is given to technicians of the processing companies. In the same way, even though there are many cooperatives that have joined in the request by the companies to have production obtained by integrated techniques, their role is still limited to resolving bureaucratic and administrative problems that come from the European Union and don't extend to the technical assistance.

With regard to the biotechnologies, the associations' most frequent statement is that the current information on risk and opportunities is too low to allow a responsible judgment on the effectiveness of their introduction in the sector.

\section{III- Public bodies for agricultural extension}

The directors of extension public bodies in Puglia and Campania are faced with diverse agricultural problems. Independent farmers have varying amounts of capital and land, as well as diverse future prospects. In Puglia, the cultivation of tomatoes does not pose any particular problems and the main job is to help farms with a high level of technical efficiency to grow. The situation in Campania is quite different. Farms are generally quite small in size, and the cultivation of tomatoes was abruptly reduced by the spread of viruses and then aggravated by the competition of Puglia. Public extension deals with the problem by teaching farmers to operate in market niches with more added value, for example by instituting collective brands (DOP,IGP) for the valorization of regional products such as San Marzano.

The position of biotechnology is uncertain: moderately favorable if directed toward resolving problems associated with viruses, and negative if oriented toward yield increasing.

\subsection{The survey at the farms}

We used a questionnaire based on the following sets of questions: general information, production processes, relationships within the cooperatives, co-ordination with backward and downward related sectors, innovation patterns, future perspectives, GMOs perception and acceptance.

Of the farms in the sample, $40 \%$ are located in Puglia (all outside Foggia) and $60 \%$ in Campania, in the Nocerino-Sarno area, the traditional territory for tomato cultivation. Farms in Puglia exhibit large sizes, with $20 \%$ of them with a cultivated area greater than 100 hectares. On the contrary, in Campania, small sizes prevail and more than $80 \%$ of the farms don't reach two hectares. In Campania farmers dedicate $50 \%$ of their cultivated area to the tomato while in Puglia tomatoes constitute no more than $10 \%$ of the land.

Many direct questions were used in order to identify the most serious problems faced while cultivating tomatoes. The answers given show that the variety cultivated, the propagation material (plants and seeds), and other technical means constitute a problem that can be overlooked, because the companies suggest the variety and the cooperatives provide technical input.

The most often declared problems are: pest desease (80\%), lack of manpower (50\%), yield reduction due to the soil impoverishment $(27 \%)$, harvest timing according to delivery organization (20\%), and irrigation (18.5\%).

Moreover, $80 \%$ of farmers highlighted institutional and economic problems stemming from the regulation of relationship with producer associations and processors in the 
framework of the UE intervention. Problems arise from the strong contractual power the intervention gives to processors and from the lack of loyalty and competence in the association conduct. Negative effects are low prices and quality and excessive market risk.

In order to identify more precisely the farmers' demand for innovation, we analyze the different weights that they give to each one of the problems described above (pest disease, lack of manpower, yield reduction due to the soil impoverishment, harvest timing according to delivery organization and irrigation), their MGOs acceptance, and the motivations supporting these choices.

We used the clustering technique in order to divide the interviewed farmers into homogeneous groups. This classification was made in two steps. In the first one, through the Principal Component Analysis we obtained few relation variables (factors) identifying relationships among more large sets of interrelated variables (elementary variables). This analysis permits to identify non-directly-observable variables (factors) based on a set of observed variables (elementary variables). These factors were obtained through orthogonal rotation of Principal Components using the Varimax method, and they are not correlated. In a second step, they were utilized as variables for a Cluster Analysis to obtain homogeneous groups of farmers. The method applied for joining clusters is the Ward's methods, and the distance among cases was computed with the squared Euclidean distance index.

The elementary variables can be classified into four main categories:

a) farm structures (land area of farms);

b) crop mix (share of tomato acreage);

c) technical aspects of tomato production process (production methods and mechanized degree of production process);

d) first year of cultivation;

e) age of the farmer.

The results are shown in table 1 . Three relational variables have an eigenvalue greater than 1 and are responsible for $78.5 \%$ of the total variation. The share of information of each elementary variable saved in the factor is expressed by communality (ranging between 0.72 and 0.84 ).

The first factor explains more than $26.9 \%$ of the total variation. It identifies the "medium farms oriented to quality production" with a high degree of mechanization, and a high quality standard of tomato crop obtained through formal integrated production methods.

The second relational variable can be defined "large farm", and it is responsible for more than $26.3 \%$ of the total variation. It joins together the farms that entered the tomato sector a long time ago. Their tomato crop area is large, but is only a spare share of total crop area. In fact, this second factor is highly correlated whit farm land, and farm share of tomato crop, but with opposite signs.

The last one $(25.3 \%$ of the total variation) is identified by two elementary variables, the farmer's age, and the first year of cultivation. Both variables are highly correlated, but with opposite signs.

In the Cluster Analysis four groups were identified.

The first one can be defined the "traditional producers", which includes $31 \%$ of the farms. They have all the traditional producer's characteristics: (a) small farms, (b) only availability of family labor, (c) labor intensive production process, (d) intensive farming system without definite rotation based on horticultural crop mix. Tomato cultivation started in the 70 s and is still based on local traditional production processes. Surprisingly, $94 \%$ of these farmers have not finished primary school, so their formal instruction level is lower than other groups. Moreover, these farmers are the oldest among interviewed farmers. Often they produce tomato crops without contracts. Generally, their market integration is very low, however the relationship between farmer and his producer association are very 
strong and reinforced by the procurement services and credit supplied to the farmer.

\begin{tabular}{|c|c|c|c|c|}
\hline & & Factor 1 & Factor 2 & Factor 3 \\
\hline & $\begin{array}{l}\% \text { of the variance } \\
\text { Cumulated variance }\end{array}$ & $\begin{array}{l}26.94 \\
26.94\end{array}$ & $\begin{array}{l}26.30 \\
53.24\end{array}$ & $\begin{array}{l}25.30 \\
78.54\end{array}$ \\
\hline Variables & Communality & & & \\
\hline $\begin{array}{l}x 1 \\
x 0\end{array}$ & 0.78 & 0.89 & & \\
\hline$x 3$ & 0.84 & & -0.87 & \\
\hline$X 4$ & 0.79 & 0.29 & 0.82 & \\
\hline$X 5$ & 0.72 & & & -0.91 \\
\hline$X 6$ & 0.81 & & 0.30 & 0.80 \\
\hline \multicolumn{5}{|c|}{${ }^{*}$ Coeffiecients lower than $+/-0.25$ are dropped } \\
\hline \multicolumn{5}{|l|}{ Legend } \\
\hline$X 1:$ & \multicolumn{4}{|c|}{ Mechanized procuction process degree } \\
\hline$X 2:$ & \multicolumn{4}{|c|}{ Processes enhancing quality } \\
\hline X3 : & \multicolumn{4}{|c|}{ Share of tomato acreage } \\
\hline$X 4:$ & \multicolumn{4}{|c|}{ Total farm area } \\
\hline X5: & \multicolumn{4}{|l|}{ Age of the farmer } \\
\hline X6 : & \multicolumn{4}{|c|}{ First year of cultivation } \\
\hline
\end{tabular}

The second group identifies the "small and medium farms" and joins more than $27 \%$ of the farmers. This group and the former are alike with respect to the farm structural aspects. Nevertheless main differences are related to some farmers' characteristics (such as age and formal instruction level) and to the part-time organization of labor, with farmers also working outside the agricultural sector. They are not efficiently market integrated and the producer association somewhat works as an exchange facilitating agency.

The third group includes the "large farms" (19\% of the sample) which alternate the tomato production with extensive crops (such as wheat). They make crop rotations, which allow the repetition of tomato only after four years. The formal instruction level is the highest of interviewed farmers, in fact more than $60 \%$ of the farmers received a middle school certificate or a university degree. The links between the farmers and the producer associations are strong, but only for services supplied to the farmer (economic and technical advice).

Finally, the fourth group puts together more than $23 \%$ of the farmers. It can be defined "high quality producers" group. Its characterizing aspects are: young farmers with a middle level of formal instruction, middle size farm, family farm with a high amount of extra-family labor. The tomato production process is oriented to an efficient use of farm labor and is mechanized from the plant to the harvest. All farms supply high quality tomatoes, using formally integrated production methods. The mechanical level of the productive process is the highest. Relationships with producers association are very strong because they give farmers all kinds of extension, including credit, managerial, technical and marketing 
services.

In table2, we present the farmers' opinions on technical and economic problems and their inclination to make use of MGOs.

\begin{tabular}{|c|c|c|c|c|}
\hline & 1st group & 2nd group & 3rd group & 4 th group \\
\hline & \multicolumn{4}{|c|}{$\%$ value } \\
\hline \multicolumn{5}{|l|}{ General problems } \\
\hline Pest control & 88 & 80 & 70 & 75 \\
\hline Labor & 35 & 66 & 60 & 41 \\
\hline Soil impoverishment & 29 & 46 & 46 & 25 \\
\hline Irrigation & 11 & 20 & 40 & 8 \\
\hline Contracts & 47 & 66 & 60 & 91 \\
\hline Associations & 23 & 20 & 90 & 58 \\
\hline UE policy & 11 & 13 & 30 & 42 \\
\hline Marketing & - & 13 & 30 & 33 \\
\hline Market opportunities & 17 & 33 & 40 & 75 \\
\hline \multicolumn{5}{|l|}{ MGOs acceptance } \\
\hline No & 83 & 54 & 60 & 67 \\
\hline Unknowen & 93 & 63 & 17 & 25 \\
\hline Comsumers' dislike & 7 & 37 & 33 & 50 \\
\hline Mistrust & - & - & 16 & 25 \\
\hline Ethical reasons & - & - & 34 & - \\
\hline Yes & 17 & 46 & 40 & 33 \\
\hline Usefull & 35 & 42 & 75 & 50 \\
\hline Experiment & 65 & 58 & 25 & 50 \\
\hline
\end{tabular}

The farms of the first group (traditional producers) perceive the pest control problem as the most important and identify the strong contractual position of the industry as the principal cause of their economic problems. Most of them (83\%) are not interested in MGOs, either because they don't have enough information (93\%), or because they do not believe in market opportunities (7\%). Among the farmers who would make use of MGOs, $65 \%$ are interested in preliminary experiments, and $35 \%$ trust the effectiveness of the new technologies.

The farmers in the second group (small and medium farms) declare three important technical problems (labor organization, yield decreasing, and virus) and many among them (66\%) complain about the strong power of processors. About 54\% dislike MGOs (lack of information, 63\%; no market opportunities, $37 \%$ ), while among the favorable ones $58 \%$ would like to experiment, and $42 \%$ believe in the effectiveness. 
The farmers in the third group (large firm) don't suffer from technical problems, while are particularly aware of the institutional distortions induced by the UE intervention. The most part $(90 \%)$ hold the producer associations responsible for low prices and marketing inefficiencies. Biotechnologies are generally disagreed $(60 \%)$, not only because of the lack of information (17\%) and of the market opportunities (33\%), but also because of ethical principles (34\%). Farmers who likes MGOs are mostly convinced $(75 \%)$ that the new technologies could have large positive economic effects.

The farmers in the fourth group are much worried about institutional problems. They criticize the behavior of producer associations (58\%) and above all the contractual power of processors (91\%). They also express the need for a wide reform of the UE policy. The interest in MGOs is quite spare and $67 \%$ of interviewed wouldn't employ it, mainly (50\%) because of marketing problems. The favorable farmers should experiment them $(50 \%)$ and believe in the potential success.

\section{THE BIOTECHNOLOGY RESEARCH IN THE PROCESSED TOMATO SECTOR.}

At present there are only a few commercial transgenic tomato, with the fruit ripening altered, that had a discrete diffusion in the US fresh market since the beginning of the nineties. We can suppose that in a few years new products will be available. The transition in the life science industry (Enriquez, Goldberg, 2000). accelerates the introduction of GMOs in as much of the market as possible and this is proved by the high number of experimental fields present in the UE. In Italy tomato is the second product (by number of experiments) in the list of UE deliberate field trials (European Commission, JRC) and it is in first place for the variety of transgenic characteristics tested. The thirty trials included in the Commission's complete list of allowed field trials (see appendix) are divided among the seven following trait innovations (numbers in brackets refer to the number of experiments per group):

- glufosinate tolerance (2);

- Bt-derived insect resistance(1);

- improvement of processing quality (6);

- increased yield(3);

- virus resistance (13);

- drought resistance (1);

- others (4).

The analysis of the groups which carry on the trials gives rise to the following remarks.

1) The research is mainly supported by the public sector. This could positively affect the distribution of potential benefits and the environmental risk control, but could compromise the commercial success of the eventual new products.

2) Multinational life-science companies are scarcely involved and this may be a result of two issues: a) tomato is not yet considered a commercially interesting market; b) Italy doesn't provide enough research facilities.

3) Seed companies are much more interested in the sector. This is because the stronger direct relationship with local customers they had over the past twenty years created major market opportunities while also giving them the possibility to exploit the organizational economies created by the existing commercial network.

4) The processing industry doesn't seem to be so fascinated by biotechnologies, in part because of the low consumer's acceptance in the UE market (that is the main market for the sector) and in part because current innovative strategies focus on different aims such as regional and organic production, quality control, and distribution organization. Moreover biotechnological research requires strong financial and knowledge resources 
while the tomato industry is a traditional sector with a low strategic and economic effort in R\&D. It could achieve some projects only by making agreements with biotech companies interested in specialty and local markets, like start-up related to the public research network, but these are just the kind of firms you cannot find in the weak socioeconomic environment of the Southern Italy.

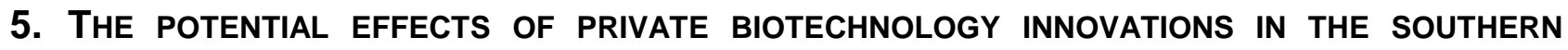 TOMATO SECTOR.}

The economic effects of biotechnology innovations in agriculture are generally evaluated looking at the user's improvement in technological efficiency (McBride, Brooks, 2000 ) and at the welfare effects. In the case of a cost reducing innovation, assuming no negative external factors, the welfare effect is measured by the change in Marshallian surplus plus the monopoly profit captured by the discoverer of the innovation through the IPR protection (Traxler, Nelson, 2000; Moschini, Lapan, 1999). While these approaches correctly capture the main effects for standardized commodities, they hardly address problems stemming from biotechnologies in specialty and processed agricultural products. When more than one sector operates in the marketing channel for the transgenic product, it's difficult to estimate the final effect on the consumer, and to evaluate the distribution of the producer's surplus among the different vertically related sectors. Monopsonistic practices in the primary market can lead to the exploitation of grower's benefits of innovation from the processing industry, likewise monopolistic power in the final market can lower the consumer's surplus. The analysis framework is even more complicated when vertical co-ordination is not achieved through the market but through contractual agreements, and when competitive strategies are based both on cost advantage and on differentiation.

We try to evaluate the potential effects of biotechnologies in the processed tomato sector by considering the strategic and organizational implications of the innovations. The analysis is strictly qualitative because of the lack of both available data and of a formal model that is able to capture the complexity of the suggested scenarios. Considering five main vertical stages in the tomato sub-sector (biotech industry, plant nurseries, growers, processors, and retail distribution) we analyse the effects of the innovations with respect to the following three issues: the vertical distribution of cost and benefits; the competitiveness of southern production; the evolution of structures and strategies within the sector. Innovations are grouped into two categories, growing improvements, and processing improvements.

\section{I- Growing improvement innovations}

The current research focuses on two characteristics, yield increase and virusresistance. A higher productivity, although technologically more efficient, could lead to economic losses from the growers. In the actual scenario with the UE support, crop abundance, instead of pulling the sector towards lower consumer prices and agriculture modernization (by the exit of marginal farmers), could worsen the contractual weakness of growers. As we have already seen, the producer associations don't try to plan the production to respect the community goals and quotas but try to depress the market to permit the maximum opportunistic exploitation from the processors. When an innovation is introduced, the growers should pay the technology fee and should accept a price lower 
than the guarantee one $\mathrm{e}^{\mathrm{T}}$. Also, consumers probably wouldn't see any advantages because the final price is imposed by the retailers according to their own cost structures and strategies 2 . Furthermore, extra profits reached by the greater market power on the procurement side could distract the industry from carrying out optimal interventions in product differentiation and quality control. Therefore the results could be: gains for the innovation suppliers and for processors; losses for the growers and maybe for the consumers that would pay for the total organizational efficiency loss. Moreover, the competitive strength of the Southern "distretto" could be worsened, because of an aggravation of the institutional problems affecting the sector and the loss of the actual Southern competitive advantages.

In the case of virus resistant plants, in the current situation with little disease loss, the effects could be compared with those of the previous case. Higher protection from virus would raise the productivity. The only additional effect would be the lower cultural risk, but under the hypothesis of risk-adverse growers this wouldn't lead to relevant economic effects. Obviously in the case of a wide disease diffusion as happened in Campania during the eighties, the innovation would be positive for all the components of the "filiera", simply avoiding an economic disaster. Nevertheless, this dramatic scenario is very unlikely also without biotechnologies, because we only need a few correct agronomic practices, such as the use of certified seed and a good crop rotation, to prevent it.

\section{II- Processing improvement innovations}

We must distinguish the case in which the innovation is introduced by the biotech industry from the case in which it is introduced by some processing firm.

In the first case, if the innovation produces cost and quality advantages we can suppose it soon will spread over the whole processing industry, causing an increase in the competitiveness, and a consumer's surplus improvement (either through a lower price, or through higher quality assurance and variety). The processor's capability to exploit some of the benefits will depend on their relative market power. Surely the main benefits will occur for the discovers and the downward suppliers of the innovation, such as the plant nursery. The main cost will be borne by growers, who will pay the technology fee and will lose strategic autonomy within the "filiera".

In the second case (innovation stemming from processing firm research activity), the effect could be a less competitive sector due to the competitive advantages achieved by the innovating firms. Probably before imitation effects are produced, consumers could lose with regard to the price but gain in product differentiation either in the horizontal or in the vertical dimension. The gains from technology fee will be shared between inventors (processors) and suppliers (the seed industry and plant nurseries) according to the specific contracts that the parties will be able to design and enforce. Growers will have to accept higher cost, nevertheless the increased strategic role of procurement activities will likely lead processors to a cooperative relationship with the farmers. In certain cases it could happen that industry would be forced to transfer part of the innovation gains to the growers to give them the incentives to cultivate the transgenic product.

\footnotetext{
${ }^{1}$ As we will discuss in the next paragraph legally processors should pay the guaranteed prices but in the system there exist a lot of informal and quite illegal ways by which the industry and the association set a different price.

${ }^{2}$ As in most processed food, the agricultural component's share on the total cost is very low and there is a low downward price transmission elasticity along the marketing channel.
} 


\section{BIOTECHNOLOGIES, LOCAL DEVELOPMENT AND INSTITUTIONAL PROBLEMS IN SOUTHERN ITALY}

One interesting result from the empirical research was that the farmer's basic need is to improve vertical co-ordination, with the aim to lower price risk and balance the buyer's contractual power.

This result demonstrates that even though it has been working for more than twenty years, the UE intervention didn't achieve the following two goals:

1) assuring farmers about production placement and price (paying the subsidy to processors should assure placement; moreover constraining the receipt of the subsidy to the payment of the target price should assure price);

2) promoting collaborative relationship among farmers (the obligation to make contracts through the producers association should help to achieve this goal) to improve the production planning and the farmers contractual position.

What really happens in the Southern regions we examined is that UE rules are only formally enforced, while exchanges are regulated by informal and implicit contracts, as the following farmers statements demonstrate:

1) price is set at the end of the harvest, according to the supply volumes;

2) processors use different ways to pay a price lower than the legal one. They can declare lower weights and quality for delivered production, or impose high rates on loans informally granted to farmers (with the producer associations acting like brokers);

3) payments timing and procedures are defined according to informal agreements that aim to maximize brokers (i.e. producer association) margins.

These informal exchange mechanisms, sometimes quite illegal, are enforced by the behavior of the associations which act as agents of processors instead of the formal principal (the farmers). This distortion in incentives can be explained noting that present directors of association previously were dealers and have been keeping the same economic behavior over time. Moreover it is a fact that the intervention gave them a strong monopsonistic power towards farmers.

Here we find most of the institutional problems that negatively affect Southern development ${ }^{3}$. The presence of informal relationships between processors and associations, enforced by traditional social conventions, somewhat constitute a form of social capital (according to the Coleman's definition). The exploitation of this social capital allow both parties to reach personal advantages by the implementation of opportunistic behaviors that damage the farmers and the public operator. Surplus stemming from these behaviors deviates system from efficiency. Competition is no more based on the achievement of competitive advantages through managerial efforts, but on the exploitation of the social capital in an opportunistic way.

These kinds of institutional problems can affect biotechnology innovations in the processed tomato sector.

The weakness of the legal system hampers investments by life-science companies, especially those made jointly with local bodies. Vice-versa, it can give rise to incentives for unfair behaviors, like a low risk control in field trials or the opportunistic exploitation of local biological resources.

\footnotetext{
3 In the eighties many studies explained the underdevelopment in Southern Italy from an institutional perspective. Some of them widely made use of the Coleman's concept of social capital (Putnam, 1993; Fukuyama, 1996), classifying the southern regions among those with a low social capital and a strong family's cultural rule. Some critics (Mutti, 1994; Bagnasco, 1994) underlined that is not the "quantity" of the social capital, but its "quality", to seriously hamper the development. This interpretation is consistent with some theoretical studies (Trigilia, 2000; Piselli, 2000; Mutti, 2000) which attempt to make the concept of social capital better fit development problems.
} 
The contractual handicap moves the agricultural sector from efficient innovative patterns, increasing the risk of adopting biotech innovations also when more suitable competing technologies could be implemented.

Finally the described vertical co-ordination forms, that lead to unfair conducts, could negatively affect any effort of the public sector to adequately inform and assure the consumers about the use (or the non-use) and the risk of MGOs.

\section{Summary and conclusions}

The empirical investigation on the possible development of biotechnologies in the processing tomato sector in Southern Italy gave rise to three main findings.

1) To date, the demand for genetically modified products is very low in the sector either because of the lack of information, or because of the need for alternative innovations. Growers look for organizational innovations that are able to increase their contractual power over the buyers. Processing firms pursue product innovations in niche markets like those for organic and regional products, and judge gm products to not be appealing enough for the consumers.

2) The interest for biotechnologies is also spare on the supply side. The life science companies are actually more interested in standardized crops than in specialty products like processed tomato. Public bodies that could achieve research projects increasing welfare, seem to be too weak both on managerial and financial grounds. The processing industry, while having some interest in gm products with added value output traits, doesn't invest enough in R\&D activities.

3) Given the actual competitive structure, the institutions acting in the sector, and the local socio-economic peculiarities, biotechnologic innovations would positively affect mainly the innovators and the operators owning the most market power along the "filiera". Growers could even suffer from innovation leading to yield increase because of the depressing market effects along with the payment of the technology fee. The most negative effect could occur in Puglia, where the agriculture competitive advantage is actually based on the natural higher productivity the region exhibits.

The achieved results suggest some discussion about two important issues.

The first topic, for which the available literature is very scant, concerns the evaluation of the relationships between the food system organisational structure and the innovative patterns in one or more vertical related stages. Some examples are given by the recent radical innovations in the food retail sector that led to revolutionary management concepts like ECR (efficient consumer response) or CM (category management) and dramatically changed the competitive framework in the backward vertical related sector (Lanciotti, 1999; Senauer, Kinsey, 1999).

In the case of the processed tomato sector, we argued that different vertical coordination forms can give different incentives to biotechnology innovation and strongly influence the distribution of derived costs and benefits among the components along the "filiera".

When the vertical co-ordination is achieved by informal and implicit contracts rather than market or formal contracts, the effects on innovating activity are even more tricky to understand. To explore this issue we need to improve the traditional efficiency-based theory (like the theory of contracts or the transaction cost economy) using analytical tools able to better tackle problems, such as the power and evolution based incentives or the social embededness of economic activity. Some analytical frameworks successfully used in local development studies as the New Economic Sociology stemming from Granovetter or the New Sociological Institutionalism (Rizza, 1999), have also recently been 
reccomanded for the food system vertical co-ordination analysis (Boon, 1999; Galizzi, Venturini, 1999).

The second issue is related to the UE regulatory options about the use of biotechnology in agriculture. The mandatory labelling option and the precautionary principle accepted in the risk assessment and management, irreconcilably opposite to the US, which instead recognizes zero-risk for GMOs (until science-based proof of dangerousness is acquired) and allows voluntary labelling of products that do not use GMOs (Caswell, 2000).

Even if people who are really worried about the negative environmental impact of GMOs would be happy to believe that UE policy is driven by the Jonas' ethical "responsibility principle", it is quite clear that UE policy is principally influenced by economic and political consensus considerations. Consensus is related to the recent interest of public opinion in food safety problems. Economic considerations refer to the UE aim of protecting domestic production, specialized in specialty and regional products, from the new transgenic products, for which the US has strong competitive advantages.

Achieved results on the potential effects of biotechnologies in the southern tomato sector allow for at least two critiques of the UE position.

Firstly, the presence of numerous field trials, in spite of the low interest in biotechnology emerging from interviews, demonstrates that in time biotechnologies will widely affect world agriculture. Than the problem is no more to ban or to write on the margin GMOs products but to responsibly and successfully participate in the science life revolution. Only if all the components of the food system are involved in the discovery and in the introduction of innovations, it will be possible to have an effective risk monitoring of the new technologies. The best aims of the public sector should than be research support and the promotion of collaborative relationships among different bodies involved in biotechnologies.

Secondly the research demonstrates that in some weak institutional frameworks (like we highlighted Southern Italy) differences between voluntary and mandatory rules are quite more theoretical than practical. When there are no market incentives to guarantee the effectiveness of the voluntary approach, and when the mandatory rules cannot be enforced by an efficient legal system, both the approaches will fail to reach their objectives (Segerson, 1999). In Southern Italy and in many underdeveloped countries with similar institutional problems (Shiva, 1993), the main public intervention should aim to improve human and social capital, by promoting knowledge and trust. 
Appendix 1a. Italy: Field Trials (EU Commission JRC) (Sourse: http://food.jrc.it/gmo)

- Tryptophan-2-monoxygenase synthesis - (Istituto Sperimentale per l'Orticoltura)

- Virus resistance (tomato spotted wilt virus) - (Istituto Sperimentale per l'Orticoltura)

- Tryptophan-2-monoxygenase synthesis - (Istituto Sperimentale per l'Orticoltura -

Section of Montanaso Lombardo)

- Virus resistance (cucumber mosaic virus) - (Istituto Sperimentale per la Patologia Vegetale; Monsanto Europe)

- Virus resistance (cucumber mosaic virus) - (Istituto Sperimentale per la Patologia Vegetale; Peto Italiana s.r.I.)

- Virus resistance (cucumber mosaic virus); Virus resistance (potato virus y) (Istituto Sperimentale per la Patologia Vegetale; Key Gene)

- Virus resistance (cucumber mosaic virus) - (Istituto Sperimentale per la Patologia Vegetale di Roma)

- Ac/Ds two componebts trasponson system; Gene tagging; Glifosinate tolerance (Metapontum Agrobios s.c.a.r.l.)

- Ac/Ds two componebts trasponson system; Glifosinate tolerance - (Metapontum Agrobios s.c.a.r.l.)

- Virus resistance (cucumber mosaic virus) - (Metapontum Agrobios s.c.a.r.l.)

- Dowregulation of pectin esterase; Improvement of processing quality - (Peto Italiana s.r.I.)

- Improvement of processing quality; Polygalacturonase synthesis - (Peto Italiana S.r.I.)

- Improvement of processing quality; Polygalacturonase synthesis - (Peto Italiana s.r.l.; Stazione Sperimentale per I'Industria delle Conserve Alimentari; Zeneca Plant Science)

- Virus resistance (cucumber mosaic virus) - (Peto Italiana s.r.l.)

- Virus resistance (cucumber mosaic virus) - (S\&G Sementi s.p.a.)

- Drought tollerane; Levan sucrase synthesis - (Sementi Nunhems s.r.l.)

- Increased cell wall thickness; Pyrophoshate synthesis - (Sementi Nunhems s.r.l.)

- Increased yield; Kinase synthesis - (Sementi Nunhems s.r.l.)

- Increased yield; Sucrose transporter protien synthesis - (Sementi Nunhems s.r.l.)

- Virus resistance (cucumber mosaic virus) - (Sementi Nunhems s.r.l.)

- Virus resistance (cucumber mosaic virus) - (SME Ricerche s.c.p.a)

- Bt-derived insect resistance - (SME Ricerche s.c.p.a)

- Dowregulation of pectin esterase; Improvement of processing quality -

- Improvement of processing quality; Polygalacturonase synthesis - (Stazione Sperimentale per I'Industria delle Conserve Alimentari)

- Improvement of processing quality; Polygalacturonase synthesis - (Stazione Sperimentale per l'Industria delle Conserve Alimentari; Zeneca Plant Science)

- Virus resistance (cucumber mosaic virus) - (Tecnogen s.c.p.a.)

- Osmotic synthesis; Pathogenesis related proteins synthesis - (Università degli Studi della Tuscia - Dipartimento di Produzione Vegetale)

- Virus resistance (tomato yellow leaf curl virus) - (Vilmorin Italia)

- Virus resistance (tomato yellow leaf curl virus) - (Vilmorin SA) 


\section{References}

ANICAV (1999). Rapporto sull'industria italiana delle conserve di pomodoro, Napoli.

Bagnasco A. (1999). Teoria del capitale sociale e political economy comparata. Stato e Mercato (57): 351-372.

Boon A. (1999). Capabilities, Transaction Costs, and Vertical Co-ordination in the Food System. In Galizzi G., Venturini L (eds.), Vertical Relationships and Co-ordination in the Food System. New York: Physica-Verlag.

Caswell J. A., (2000). An Evaluation of Risk Analysis as Applied to Agricultural Biotechnology (with a Case Study of GMO Labeling). Agribusiness 16 (1): 115-123.

Coleman J. S. (1990). Foundation of Social Theory. Cambridge: Harvard University Press.

Enriquez J., Goldberg R. A. (2000). Transforming Life, Transforming Business: The LifeScience Revolution. Harvard Business Review (4): 96-104.

Falck Zepeda J.B., Traxler G., Nelson R.G. (2000). Rent Creation and Distribution from Biotechnology Innovations: the case of Bt Cotton and Herbicide-Tolerant Soybean in1997. Agribusiness 1 (16): 21-32.

Fukuyama, F. (1995). Trust. New York. The Free Press.

Galizzi G., Venturini L. (1999), Towards a Theory of Successful Vertical Cooperation in the Food System. In Galizzi G., Venturini L (eds.), Vertical Relationships and Co-ordination in the Food System. New York: Physica-Verlag.

INEA (2000). Le proposte di riforma del sostegno al pomodoro da industria e agli agrumi destinati alla trasformazione. Roma.

Jonas H. (1990). II principio responsabilità. Torino: Einaudi.

Lanciotti C. (1999). Supply Chain Integration, Category Management and the Italian Food Retail Sector. In Galizzi G., Venturini L (eds.), Vertical Relationships and Co-ordination in the Food System. New York: Physica-Verlag.

Moschini G., Lapan H. (1999). Intellectual Property Rights and the Welfare Effects of Agricultural R\&D. In Galizzi G., Venturini L (eds.), Vertical Relationships and Coordination in the Food System. New York: Physica-Verlag.

Mutti A. (1994). I sentieri dello sviluppo. Rassegna italiana di sociologia. (73): 109-120.

Mutti A. (1998). Capitale sociale e sviluppo. Bologna: il Mulino.

Pelt J-M. (2000). L'orto di Frankestein. Milano. Feltrinelli.

Piselli F. (1999). Capitale sociale: un concetto situazionale e dinamico. Stato e Mercato (57): 395-417.

Putnam R. (1993). Making Democracy Work. Princeton: Princeton University Press.

Rizza R. (1999). Le istituzioni tra Economia e sociologia. Sociologia del Lavoro. (73): 119143.

Segerson K. (1999). Mandatory Versus Voluntary Approaches to Food Safety. Agribusiness 1 (16): 53-70.

Senauer B., Kinsey J. (1999). The Efficient Consumer Response Initiative: Implications for Vertical Relationships Throughuot the U.S. Food System. In Galizzi G., Venturini L (eds.), Vertical Relationships and Co-ordination in the Food System. New York: Physica-Verlag.

Shiva V. (1993). Monoculture of the Mind. Perspectives on Biodiversity and Biotechnology. London: Zed Books.

Trigilia C. (1999). Capitale sociale e sviluppo locale. Stato e Mercato (57): 419-440. 